\title{
Management of the asphyxiated full term infant
}

\author{
Malcolm I Levene
}

In Britain, approximately one full term baby per thousand dies or is severely disabled as the result of birth asphyxia. It is arguably the most important avoidable cause of permanent neurological injury affecting the mature fetus/newborn. It is generally agreed that clinical signs of hypoxic-ischaemic encephalopathy (HIE) are the best markers for a tunately the severity of HIE can only be diagnosed retrospectively after symptoms have developed. Early therapeutic intervention in the asphyxiated baby may be important to modify cerebral injury (see below) and therefore there remains a need to have early markers of asphyxia such as depressed Apgar scores, delay in establishing respiration, or evidence of significant metabolic acidosis on samples of cord blood.

Although there appears to have been a fall in both the incidence of HIE and the number of children disabled by this condition in recent years, ${ }^{1}$ there is little evidence that this has been due to improvement in postnatal management. In this paper I will consider the standard management of asphyxia, potentially useful new methods for treating the asphyxiated brain, and consider methods of deciding when to withdraw care. The brain of the full term infant responds to asphyxia in a very different manner to that of a premature baby and this paper only considers the management of asphyxia in full term infants.

Rational basis of standard management Asphyxiated infants require expert and rapid resuscitation wherever they are born. All health care professionals involved in the birth of babies must be adequately trained and retrained in resuscitation techniques. In most cases 'bag and mask' is sufficient to maintain ventilation until someone with advanced resuscitation skills arrives. Appropriate cardiovascular support must be available for infants born with poor or absent circulation. The table summarises an approach to the management of the asphyxiated full term infant.

Academic Unit of

Paediatrics and Child Health, University of Leeds, D Floor,

Clarendon Wing, The General Infirmary at Leeds, Leeds LS2 9NS

Correspondence to:

Professor Levene.

It has been shown that a raised blood glucose concentration before hypoxic-ischaemic injury in adolescent animals results in more extensive cerebral injury than in those with normal or low blood glucose. ${ }^{2}$ This has had diagnosis of intrapartum 'asphyxia'. Unfor-

the effect of making paediatricians very cautious in the use of intravenous glucose during neonatal resuscitation. More recent data has shown conclusively that there is a fundamental difference in the way the immature and the more mature brain responds to glucose infusion. This is probably in the main related to the impaired rate of glucose transport across the immature blood-brain barrier. The immature brain appears to be protected by raised glucose concentrations before asphyxial insult compared with animals that had no additional glucose. ${ }^{3}$ There is conflicting data concerning the brain protective effect of high glucose concentrations after asphyxia. In an immature animal model, administration of glucose immediately after a period of hypoxicischaemic insult resulted in significant reduction in cerebral infarction, ${ }^{4}$ but others have shown that in a slightly different rat pup model there was significant exacerbation of damage in the presence of hyperglycaemia after injury. ${ }^{5}$

Hypoglycaemia must be avoided during and after resuscitation of asphyxiated babies, but faced with conflicting reports on the role of glucose infusion after hypoxic-ischaemic injury it is not possible at the present time to give practical advice concerning the role of glucose infusion after human birth asphyxia. This question would be best answered in a double blind controlled clinical study.

PREVENTION OF CEREBRAL OEDEMA

It is widespread practice to anticipate cerebral oedema and manage the baby so as to reduce the possibility that this complication may develop. This is done in two ways. Firstly, a

Summary of management of severe birth asphyxia. See text for details

Immediate management:

1. Establish effective ventilation

2 . Assist circulation if necessary

Early management:

1. Restrict fluids by $20 \%$ for first two days

2. Monitor blood pressure and treat hypotension vigorously 3. Assess respiratory effort and

(a) ventilate if baby breathing spontaneously with arteria carbon dioxide tension $>7 \mathrm{kPa}$

(b) if baby ventilated maintain arterial carbon dioxide tension at $4.5 \mathrm{kPa}$

mannitol $1 \mathrm{~g} / \mathrm{kg}$ over 20 minutes and repeat if necessary mannitol $1 \mathrm{~g} / \mathrm{kg}$

Anticonvulsants if:

1. Frequent convulsions $>3$ per hour

2. Prolonged convulsions lasting $\geq 3$ minutes 
regimen of fluid restriction is often instituted and secondly corticosteroids are administered.

\section{Fluid restriction}

There have been no studies on the effect of fluid restriction in infants with cerebral oedema. In general, measures to reduce cerebral oedema probably have no effect on long term neurological outcome (see below) and it is difficult to argue that routine fluid restriction has any advantage in this respect.

Fluid restriction may be important in asphyxiated infants who have complications such as inappropriate secretion of antidiuretic hormone and renal compromise. Fluid retention occurring as the result of these two conditions may further compromise the infant and for these reasons I recommend restricting fluids by $20 \%$ of the normal regimen for the first two days of life or until such time as the baby's renal function recovers.

Hypotension is a relatively common complication of birth asphyxia and may be due to reduction of the circulating blood volume and therapeutic dehydration may exacerbate this condition. Plasma infusion may be required in hypotensive asphyxiated infants. Hypoglycaemia and overt dehydration as a result of fluid restriction must be avoided.

\section{Corticosteroids}

There are no data to support the use of corticosteroids in the routine management of birth asphyxia. Studies in adults and in animal models have failed to show any benefit in reducing brain swelling or improving outcome. In animal models of asphyxia, corticosteroids have shown either a detrimental effect ${ }^{6}$ or no benefit at all. ${ }^{7}$ Corticosteroids are associated with a number of actual or potential side effects including hyperglycaemia, hypertension, susceptibility to infection, gastrointestinal haemorrhage, and restriction of later brain growth. In my view, corticosteroids should not be used in the management of birth asphyxia.

MANAGEMENT OF CEREBRAL OEDEMA In very severely asphyxiated infants, raised intracranial pressure (ICP, a sustained increase to $1.33 \mathrm{kPa}(>10 \mathrm{~mm} \mathrm{Hg})$ ) lasting for 20 minutes or more occurs in $70 \%$ of cases. ${ }^{8}$ The management of intracranial hypertension includes hyperventilation (lowering of the arterial carbon dioxide tension) and infusion of osmotic agents.

\section{Hyperventilation}

Hyperventilation lowers ICP by cerebral vasoconstriction with reduction of cerebral blood volume and consequent decrease in total intracranial volume. An important component of the pathophysiology of postasphyxial injury is cerebral hypoperfusion and it is possible that hyperventilation may exacerbate impaired reperfusion to the brain. There have been no clinical trials of hyperventilation in the asphyxiated newborn. Babies who have suffered significant birth asphyxia may spontaneously hypoventilate with resulting hypercapnia and increased cerebral blood volume which is probably undesirable. For this reason all encephalopathic babies should have an arterial carbon dioxide tension measurement and if this is $>7 \mathrm{kPa}(53 \mathrm{~mm} \mathrm{Hg}$ ) then the baby should be electively ventilated. The mechanical ventilator should be adjusted to maintain the arterial carbon dioxide tension at about $4.5 \mathrm{kPa}$ (34 $\mathrm{mm} \mathrm{Hg}$ ).

\section{Osmotic agents}

Osmotic agents (mannitol or glycerol) are used to reduce cerebral oedema by increasing serum osmolality. In a neonatal animal model mannitol significantly reduced brain water content when given immediately after an hypoxicischaemic event, ${ }^{9}$ but it did not reduce the severity of distribution of brain damage in treated compared with untreated animals. There have been no neonatal randomised controlled studies of mannitol or glycerol in the management of intracranial hypertension. Marchal et al in an uncontrolled study gave mannitol to 225 babies with the diagnosis of asphyxia, ${ }^{10}$ although the precise indications for treatment were quite varied. Early treatment was defined as mannitol infusion $(1 \mathrm{~g} / \mathrm{kg})$ before the baby was 2 hours of age. There were significantly fewer deaths $(p=0.005)$ and the survivors had better neurological outcome $(p=0.014)$ in the early treatment group compared to those treated after 2 hours. Levene and Evans showed that mannitol $(1 \mathrm{~g} / \mathrm{kg}$ over 20 minutes) reduced ICP in a small number of severely asphyxiated infants with intracranial hypertension $(>1.33 \mathrm{kPa}$ or $>10 \mathrm{~mm} \mathrm{Hg}) .{ }^{11}$ There was a concomitant rise in cerebral perfusion pressure 60 minutes after starting the mannitol infusion. The effect of mannitol lasted for approximately four hours.

Providing there is adequate renal function to allow excretion of mannitol, it appears to be a relatively safe agent in the management of cerebral oedema. Its efficacy remains in doubt, but I would recommend its use in infants with a bulging fontanelle or in whom there is the clinical impression of intracranial hypertension.

There are very few studies to evaluate the role of intracranial pressure monitoring and management of intracranial hypertension. Non-invasive methods for measuring ICP are unreliable in giving accurate measurements of pressure. Levene et al reported that in a group of 23 babies who had direct subarachnoid pressure recordings, knowledge of the actual ICP reading might have altered management to the benefit of the patient in only $9 \%$ of cases. ${ }^{8}$ The routine use of ICP monitoring cannot be recommended.

\section{ANTICONVULSANT TREATMENT}

Convulsions occur commonly after birth asphyxia and anticonvulsant drugs are the most widely used pharmacological agents in 
the management of infants with birth asphyxia. The immature brain appears to develop convulsions at a significantly lower threshold than the more mature brain. ${ }^{12}$ Seizures cause a doubling in cortical metabolic rate and it has been suggested that this causes further neuronal injury as a result of relative substrate depletion. In immature animal models, the induction of status epilepticus caused a marked reduction in eventual brain weight and reduced cerebral DNA concentration. ${ }^{13}$

Despite these studies, controversy exists as to whether neonatal seizures simply reflect neuronal compromise or whether the convulsions contribute to further neuronal loss. There are no human data to support the latter concept. Nevertheless, the use of multiple anticonvulsants is very common in the asphyxiated neonate and it is clear that exposure of the neonatal brain to these drugs may be associated with adverse effects. ${ }^{14}$

There have been few controlled studies on the use of anticonvulsants in the neonatal period. Goldberg et al treated a group of asphyxiated infants with a continuous infusion of thiopentone and compared the outcome with a similar group treated by standard anticonvulsants. ${ }^{15}$ There were no significant differences in outcome, but 14 of the 17 infants given thiopentone treatment required inotrope support for hypertension compared with only seven of 15 controls.

Although there is no scientific evidence that anticonvulsants improve outcome after neonatal convulsions due to birth asphyxia, it is clinically difficult not to treat infants with neonatal convulsions. In my view, it is not necessary to abolish all convulsions, but treatment should be instituted for frequent ( $>3$ convulsions per hour) or prolonged convulsions (any fit lasting $\geqslant 3$ minutes). I recommend phenobarbitone as the first line anticonvulsant (20 $\mathrm{mg} / \mathrm{kg}$ loading dose followed by $3 \mathrm{mg} / \mathrm{kg}$ every 12 hours). If frequent or prolonged convulsions continue then a second half loading dose can be given $(10 \mathrm{mg} / \mathrm{kg})$. Clonazepam is used as a second line anticonvulsant $(100 \mu \mathrm{g} / \mathrm{kg}$ loading dose which can be followed by a continuous infusion of $10 \mu \mathrm{g} / \mathrm{kg} /$ hour if necessary). Anticonvulsants can be stopped once the infant is thought to be neurologically normal on clinical examination.

There are no data on the clinical significance of electroconvulsive seizure activity in asphyxiated infants with reference to subsequent outcome. Electroencephalographic monitoring of infants may give very important prognostic information (see below), but I do not believe that it is yet a useful clinical technique for deciding which infants to treat or when to start anticonvulsant treatment.

\section{New treatments}

It is of considerable interest that the neuron is remarkably resistant to asphyxial insult and may recover to generate electrical potentials even after an hour of severe hypoxic-ischaemic insult. Evidence from magnetic resonance spectroscopy studies in asphyxiated neonates suggest that there is progressive and permanent degradation of high energy ATP molecules within the brain, but no abnormalities can be detected on magnetic resonance spectroscopy for up to 24 hours after the insult. ${ }^{16}$ Measurement of cerebral blood flow velocity by Doppler ultrasound has shown that an abnormal signal which accurately predicts severe cerebral injury only becomes abnormal 24 hours after the asphyxial event. ${ }^{17}$ These observations support the evidence from animal models that asphyxia sets up a cascade of intracellular events which causes the neuron to die some hours after the acute insult. The process of reoxygenation and reperfusion after asphyxia appears to be the spark that ignites the fuse to eventual neuronal death. Recent research has suggested a number of pathways by which this damage occurs and therapeutic strategies are suggested by this work. Two pathways that offer promise of protecting the perinatal human brain are (i) that which prevents free radical damage and (ii) that which causes the antagonism of excitatory neurotransmitters.

FREE RADICAL INJURY

A free radical is a highly energetic substance which contains an uneven number of electrons in its outer ring. Two free radicals, the superoxide $\left(\mathrm{O}_{2}^{-}\right)$and the hydroxyl ( $\left.\mathrm{OH}\right)$, are generated by oxygen metabolism. Their half lives are very short, but they may under certain circumstances generate chain reactions of free radicals which cause damage to cellular membranes. Naturally occurring free radical scavengers exist to limit the production of these substances, but these may be overwhelmed after asphyxial compromise.

During hypoxic-ischaemic insult, free radicals are produced by the process of degradation of ATP. On reperfusion of the tissues xanthine oxidase metabolises molecular oxygen to produce oxygen free radicals. The main source of xanthine oxidase in the brain is the endothelial cell. Free radicals are also produced in the cortex after asphyxia as the result of arachidonic acid metabolism. After an asphyxial injury of the immature animal, indomethacin has been shown to inhibit the production of free radicals in the brain. ${ }^{18}$ Allopurinol is a free radical scavenger and also inhibits the enzyme xanthine oxidase. Palmer et al have shown that treatment with allopurinol before an asphyxial insult reduces both brain swelling and structural damage in the perinatal brain. ${ }^{19}$

\section{GLUTAMATE RELATED INJURY}

Glutamate is an excitatory neurotransmitter that is particularly ubiquitous in the developing brain. The glutamate neuroreceptor is stimulated by at least three ligands, of which $N$ methyl-D-aspartate (NMDA) opens a receptor operated channel which allows calcium to enter the neuron. Asphyxia causes excessive release of glutamate from the presynaptic vesicles and inhibits uptake of glutamate from 
the synaptic cleft. This causes hyperstimulation of the glutamate receptors resulting in early and late damage to the cell. Abnormal stimulation of the non-NMDA receptors causes entry of excess sodium and water into the cell shortly after the asphyxial injury leading to cytotoxic oedema. Neuronal death occurs later and appears to be more closely related to excessive stimulation of the NMDA receptors which causes accumulation of toxic concentrations of calcium within the neuron. This leads to a cascade of biochemical events, including activation of intracellular proteases and lipases with the secondary effect of generation of oxygen free radicals which in turn cause further damage to intracellular membranes.

A group of substances antagonise the NMDA channel and protect the perinatal brain after asphyxia. ${ }^{20}$ One such substance, MK-801, when given after an NMDA insult resulted in $95 \%$ protection of the brain..$^{21}$ Even when given 120 minutes after the insult there was some protection. ${ }^{22}$ Unfortunately, MK801 and other NMDA receptor antagonists are highly toxic. Magnesium appears to be a naturally occurring antagonist which has a receptor site deep within the calcium channel. It has been suggested that increasing the extracellular neuronal magnesium concentration may protect the brain against hypoxicischaemic insults by an action similar to NMDA receptor antagonists. It has been shown that treatment with magnesium sulphate up to an hour after excessive exposure to a NMDA-like compound protected the animal against neurological sequelae. ${ }^{23}$ Magnesium sulphate is a substance that has been widely used for over 60 years in perinatal practice as a treatment of premature labour and severe pre-eclamptic toxaemia. It seems to be well tolerated by the fetus and newborn infant, although transient hypotonia and lethargy are commonly seen for a few days afterwards.

There are no published data on the use of NMDA antagonists in the human neonate, but the role of magnesium sulphate deserves active consideration as a neuroprotective agent for use after birth asphyxia.

\section{The role of brain imaging}

There are two indications for imaging the brain of asphyxiated newborn infants. The first is to discover a treatable complication of the asphyxia; most notably a subdural collection. In my experience, subdural haemorrhage severe enough to require surgical treatment occurs in $<5 \%$ of full term asphyxiated infants. An early ultrasound scan within 12 hours of birth will detect a midline shift if there is a significant lesion. As there appears to be no rational basis for the systematic management of cerebral oedema, frequent ultrasound or computed tomography to detect this are of no value.

Imaging the brain may be of value in the prediction of outcome. Extensive areas of decreased radiodensity have been shown to be a good prognostic indicator of death or severe handicap. Two studies have reported a sensitivity of this finding of $90 \%$ and $91 \%$ respectively. ${ }^{2425}$ It is of interest that prognosis using computed tomography is reliable only in the second week of life. ${ }^{26}$

\section{Prognosis}

The aggressive early management of the severely asphyxiated infant may be tempered by consideration of the eventual outcome of the baby and the risk of severe disability. The question relating to prognosis may arise at two different times during the course of the infant's management.

\section{(1) WHEN SHOULD RESUSCITATION STOP?}

If an infant has no cardiac output after 10 minutes of effective resuscitation then treatment should be abandoned. There is no consensus view as to how long resuscitation should continue if the baby has a good cardiac output yet has failed to breathe spontaneously. There are reports in the literature of babies not establishing spontaneous respiration by 20 minutes and surviving to be normal. In a Swedish study $25 \%$ of surviving babies who had not breathed spontaneously by 20 minutes were without significant handicap. ${ }^{27}$

The literature and individual experience suggests that the prognosis for normal or near normal survival if the baby has not breathed for 30 minutes after birth is poor. Peliowski and Finer have reviewed the literature and report the outcome of only 35 full term babies who did not breathe spontaneously by 30 minutes and $24(80 \%)$ died or were significantly handicapped. ${ }^{28}$ Unfortunately, many of the data on time to respiration are anecdotal and policies based on time to achieve spontaneous respiration must be recognised as being prone to serious prejudice.

Depression of Apgar scores are also a relatively poor predictor of adverse outcome. An overview of three studies reporting mortality and morbidity in infants with Apgar scores of 3 or less at five minutes showed that this carried an overall risk of mortality of $16 \%$, but only a 3\% risk of handicap in surviving infants. ${ }^{28}$ Another study reported that the best predictor of death or handicap was an Apgar score of 5 or less at 10 minutes. ${ }^{29}$

As it is usually inexperienced medical staff who are called to the delivery suite to resuscitate asphyxiated babies, I advise that if there is any doubt as to whether to continue resuscitation the baby should be given the benefit of the doubt and transferred to a neonatal intensive care unit for further management and observation. It may be possible to give a more accurate prediction of outcome later than immediately after birth (see below).

\section{(2) WHEN SHOULD MECHANICAL VENTILATION} BE WITHDRAWN?

Signs of irreversible cerebral injury may be delayed for many hours and accurate and honest prognostication may have to be delayed 
up to 24 hours. The severity of HIE has been shown to be the most accurate clinical predictor of outcome after birth asphyxia in full term infants. ${ }^{29}$ Unfortunately, the maximal degree of HIE may not be determined until the baby is a few days old and it therefore cannot be used as an early predictor of outcome. A number of tests have been shown accurately to predict outcome when performed within 24 hours of life.

Experiments in the developing brain have shown that asphyxia causes a sequence of abnormalities in the electroencephalogram. This includes an initial period of depressed electrical activity lasting approximately eight hours, followed by a period of epileptiform activity and culminating in loss of intensity at all frequencies by 72 hours. ${ }^{30}$ The final pattern of low activity correlated with severe neuronal damage. ${ }^{31}$ In human neonates, similar severe abnormalities on the electrocephalogram or cerebral function monitor including burst suppression, sustained low voltage, and isoelectric activity have also been shown to correlate with an overall risk of $95 \%$ for adverse outcome. ${ }^{28}$ The time scale for these severe abnormalities to develop appears to be shorter in the human than in the animal model.

Severely abnormal evoked potentials also accurately predict adverse outcome, although prediction of outcome in the first 24 hours using these techniques is not reliable. ${ }^{32} 33 \mathrm{We}$ have shown that abnormally high cerebral blood flow velocity detected by duplex Doppler ultrasound has a positive predictive value of $94 \%$ for adverse outcome (death or severe handicap) when performed in the first 24 hours of life. ${ }^{17}$

The presence of severely abnormal results on electroencephalography or Doppler assessments in the first 24 hours appears to predict accurately bad outcome and I advise that these tests be repeated twice in the first 24 hours and if on both occasions the results are unequivocally abnormal then the poor prognosis should be explained to the parents and consideration given to withdrawing ventilatory support if this is appropriate.

1 Hull J, Dodd KL. Falling incidence of hypoxic-ischaemic encephalopathy in term infants. Br $\mathcal{f}$ Obstet Gynaecol 1992; 99: 386-91

2 Myers RE, Yamaguchi S. Nervous system effects of cardiac arrest in monkeys. Preservation of vision. Arch Neurol 1977; 34: 65-74.

3 Vannucci RC, Mujsce DJ. Effect of glucose on perinatal hypoxic-ischemic brain damage. Biol Neonate 1992; 62: 215-24.

4 Hattori H, Wasterlain CG. Posthypoxic glucose supplement reduces hypoxic-ischemic brain damage in the neonatal rat. Ann Neurol 1990; 28: 122-8.

5 Sheldon RA, Partridge JC, Ferriero DM. Postischemic hyperglycemia is not protective to the neonatal rat brain. hyperglycemia is not protective
Pediatr Res 1992; 32: 489-930.

6 Altman DI, Young RS, Yagel SK. Effects of dexamethasone in hypoxic ischemic brain injury in the neonatal rat. Biol in hypoxic ischemic brain in

7 De Souza SW, Dobbing J. Cerebral oedema in developing brain. III. Brain water and electrolytes in immature asphyxiated rats treated with dexamethasone. Biol Neonate 1973; 22: 388-97.

8 Levene MI, Evans DH, Forde A, Archer LNJ. Value of intracranial pressure monitoring of asphyxiated newborn infants. Dev Med Child Neurol 1987; 29: 311-9.

9 Mujsce DJ, Stern DR, Vannucci RC, Towfighi J, Hershey PA. Mannitol therapy in perinatal hypoxic-ischemic brain damage. Ann Neurol 1988; 24: 338

10 Marchal C, Costagliola P, Leveau P, Dulcq P, Steckler R, Rouquier F. Traitement de la souffrance cerebrale neonatale d'origine anoxique par le mannitol. Revue Pediatrie 1974; 9: 581-90.

11 Levene MI, Evans DH. Medical management of raised intracranial pressure after severe birth asphyxia. Arch Dis Child 1985; 60: 12-6.

12 Jensen FE, Applegate CD, Holtzman D, Belin TR, Burchfiel JL. Epileptogenic effect of hypoxia in the immature rodent brain. Ann Neurol 1991; 29: 629-37.

13 Wasterlain CG. Effects of neonatal status epilepticus on rat brain development. Neurology 1976; 26: 975-86.

14 Levene MI. Neonatal seizures. Neonatal neurology. Current reviews in paediatrics. Edinburgh: Churchill Livingstone, 1987: 201-38.

15 Goldberg R, Moscoso P, Bauer C, et al. Use of barbiturate therapy in severe perinatal asphyxia: a randomized controlled trial. $\mathcal{\exists}$ Pediatr $1986 ; 109: 851-6$.

16 Wyatt JS, Edwards AD, Azzopardi D, Reynolds EOR. Magnetic resonance and near infrared spectroscopy for investigation of perinatal hypoxic-ischaemic brain injury. investigation of perinatal hypoxic-is

17 Levene MI, Fenton AC,. Evans DH, Archer LNJ, Shortland DB, Gibson NA. Severe birth asphyxia and abnormal cerebral blood-flow velocity. Dev Med Child Neurol 1989; 31: 427-34.

18 Pourcyrous M, Leffler CW, Mirro R, Busija DW. Brain superoxide anion generation during asphyxia and reventilation in newborn pigs. Pediatr Res 1990; 28: 618-21.

19 Palmer C, Vannucci RC, Towfighi J. Reduction of perinatal hypoxic-ischemic brain damage with allopurinol. Pediatr Res 1990; 27: 332-6.

20 Levene MI. Role of excitatory amino acid antagonists in the management of birth asphyxia. Biol Neonate 1992; 62: 248-51.

21 McDonald JW, Roeser NF, Silverstein FS, Johnston MV. Quantitative assessment of neuroprotection against NMDA-induced brain injury. Exp Neurol 1989; 106: 289-96.

22 McDonald JW, Silverstein FS, Cardona D, Hudson C, Chen R, Johnston MV. Systemic administration of MK801 protects against N-methyl-D-aspartate and quisqualate-mediated neurotoxicity in perinatal rats. Neuroscience 1990; 36: 589-99.

23 Wolf G, Keilhoff G, Fischer S, Hass P. Subcutaneously applied magnesium protects reliably against quinolinateinduced $\mathrm{N}$-methyl-D-aspartate (NMDA)-mediated neurotherapeutical implications? Neurosci Lett 1990; 117: 207-11.

24 Adsett DB, Fitz CR, Hill A. Hypoxic-ischemic cerebral injury in the term newborn: correlation of CT findings with neurological outcome. Dev Med Child Neurol 1985; 27: $155-60$.

25 Lipper EG, Voorhies TM, Ross G, Vannucci RC, Auld P. Early predictors at one-year outcome for infants asphyxiated at birth. Dev Med Child Neurol 1986; 28: 303-9.

26 Lipp-Zwahlen AE, Deonna T, Chrzanowski R, Micheli JL, Calame A. Temporal evolution of hypoxic-ischaemic brain lesions in asphyxiated full-term newborns assessed by computerized tomography. Neuroradiology 1985; 27: $138-44$.

27 Ergander U, Eriksson M, Zetterstrom R. Severe neonatal asphyxia: incidence and prediction of outcome in the asphyxia: incidence and prediction of outcome in the

28 Peliowski A, Finer NN. Birth asphyxia in the term infant. In: Sinclair JC, Bracken MB, eds. Effective care of the newborm infant. Oxford: Oxford University Press, 1992: 249-80

29 Levene MI, Sands C, Grindulis H, Moore JR. Comparison of two methods of predicting outcome in perinatal asphyxia. Lancet 1986 ; i: $67-8$.

30 Williams CE, Gunn AJ, Mallard C, Gluckman PD. Outcome after ischemia in the developing sheep brain: an electroencephalographic and histological study. Neurology 1992; 31: 14-21.

31 Williams CE, Gunn AJ, Synek B, Gluckman PD. Delayed seizures occurring with hypoxic-ischemic encephalopathy in the fetal sheep. Pediatr Res 1990; 27: 561-5.

32 Gibson NA, Brezinova V, Levene MI. Somatosensory evoked potentials in the term newborn. Electroencephalogr Clin Neurophysiol 1992; 84: 26-31.

33 Taylor MJ, Murphy WJ, Whyte HE. Prognostic reliability of somatosensory and visual evoked potentials of asphyxi-
ated term infants. Dev Med Child Neurol 1992; 34: 507-15. 